\title{
Phosphorus cycling through phosphine in paddy fields
}

\author{
Sheng-Hui Han ${ }^{\mathrm{a}}$, Ya-Hui Zhuang ${ }^{\mathrm{a}, *}$, Ji-Ang Liu ${ }^{\mathrm{b}}$, Dietmar Glindemann ${ }^{\mathrm{c}}$ \\ a Air Pollution Control Laboratory, Research Center for Eco-Environmental Sciences, Chinese Academy of Sciences, \\ P.O. Box 2871, Beijing 100085, PR China \\ ${ }^{\mathrm{b}}$ State Key Laboratory for Environmental Aquatic Chemistry, Academy of Sciences, P.O. Box 2871, Beijing 100085, PR \\ China \\ ${ }^{\mathrm{c}}$ Institute of Animal Hygiene and Veterinary Public Health, University of Leipzig, Leipzig, Germany
}

Received 24 February 2000; accepted 26 May 2000

\begin{abstract}
Phosphine emission fluxes from paddy fields, phosphine ambient levels in air, and the vertical profile of matrix-bound phosphine in soil have been measured throughout the growing season of rice in Beijing, China. It was found that both the seasonal and diurnal emission fluxes and ambient levels fluctuate significantly. During the drainage period, phosphine released from the soil with the highest diurnal average flux on the first period of drainage (approx. $17.7 \mathrm{ng} \mathrm{m}^{-2} \mathrm{~h}^{-1}$ ), whereas its highest ambient level (approx. $250 \mathrm{ng} \mathrm{m}^{-3}$ ) occurred at $06.00 \mathrm{~h}$. During the flooded period, phosphine emission was low, and the peaks of phosphine emissions occurred at midnight. The average flux of $\mathrm{PH}_{3}$ emission for the whole season was found to be approximately $1.78 \mathrm{ng} \mathrm{m} \mathrm{m}^{-2} \mathrm{~h}^{-1}$. The mass fraction of matrix-bound phosphine is approximately $0.18 \sim 1.42 \times 10^{-7}(\mathrm{~m} / \mathrm{m})$ part of organic phosphorus or $3.4 \sim 9.2 \times 10^{-9}(\mathrm{~m} / \mathrm{m})$ part of total phosphorus in paddy soil. The amount of phosphine emitted to the atmosphere was only a small fraction of the phosphine that remained in the soil in the matrix-bound form. Soil serves both as the source and the sink of $\mathrm{PH}_{3}$. C) 2000 Elsevier Science B.V. All rights reserved.
\end{abstract}

Keywords: Phosphine; Emission fluxes; Paddy field; Matrix-bound

\section{Introduction}

The occurrence of phosphine in the natural environment, as well as its role in the biogeochemical cycling of phosphorus, has been in dispute for nearly half a century. Tsubota (1959) failed to obtain convincing evidence of phosphine

\footnotetext{
* Corresponding author. Tel.: + 86-10-6292-3564; fax: + 8610-6292-3563.

E-mail address: zhuangyh@sun.ihep.ac.cn (Y. Zhuang).
}

formation in paddy fields because of his primitive analytical technique for phosphine. Only several decades later, David et al. (1988) succeeded to identify phosphine in the volatile compounds emitted from sewage plants. In the last decade, Glassmann and Glindemann improved the enrichment and analytical techniques for ambient phosphine. They measured phosphine in the emissions from waste digestion, animal manure, marsh gas, and landfill sites as well as the 'matrix-bound' phosphine contained in anaerobic 
sediments, sludges and soils (Gassmann and Schorn, 1993; Gassmann, 1994; Glindemann and Bergmann, 1995; Glindemann et al., 1996a,b; Devai and Delaune, 1995). Glindemann et al. (1996a) detected the existence of phosphine in the ambient air. The formation mechanism was also tackled (Eismann et al., 1997b).

Liu et al. (1999) detected phosphine in sediment samples and in ambient air adjacent to a paddy field in Beijing, challenging the previous unsuccessful attempts to identify phosphine in paddy field emissions. Since China has large areas of paddy fields and numerous eutrophic water bodies, the ambient levels of phosphine in Beijing are relatively high compared with those in Germany and South America. This implies hitherto unknown but important phosphorus cycling processes, which might have both positive and negative effects on the biomass growth in Chinese croplands and forests. In view of the fact that phosphine is an intermediate of anaerobic processes in soil, its subsequent oxidation to phosphoric acid is actually an activation process of soil phosphorus originally unavailable to plants. This is an overlooked positive aspect of phosphine on plant growth. Phosphine is also a reactive atmospheric trace gas, which competes with methane and other greenhouse gases for hydroxyl radicals and thus, enhances an indirect greenhouse effect, or the so-called coupling effect (Prinn, 1994). On the other hand, phosphine itself is a toxic substance, which inhibits the growth of soil microorganisms and damages crop roots. These toxic effects would not only influence the emissions fluxes of other greenhouse gases from soil, but also could cause disturbance in the rhizosphere. Cao et al. (2000) have studied the possible phosphine formation mechanism in the environment. However, no quantitative information on phosphine emission fluxes from soil has been reported. In this paper, we measured the seasonal and diurnal changes of phosphine emission fluxes from paddy fields in a suburb of Beijing.

\section{Experimental}

\subsection{Sampling site and cultivation practice}

Field studies were carried out from 28 May to 8 October 1999 at a paddy-field site located at Houbajia in the Haidian District of Beijing, China. The total area of this field was approximately 13.5 ha. It was irrigated solely with domestic sewage water. No chemical fertilizer was applied. Flooding was done right before transplanting. The rice seedlings were raised in seedling beds and trans-

Table 1

Field practices and rice growing stages

\begin{tabular}{|c|c|}
\hline Event & Dates \\
\hline 1st Flooding period & 1 May-1 July \\
\hline Transplanting & 15 May-25 May (much water in the field) \\
\hline Tillering stage & 25 May-1 July (24 June-1 July little water in the field) \\
\hline 1st Draining period & 2 July-29 July (no water in the field) \\
\hline $\begin{array}{l}\text { 2nd Flooding period } \\
\text { (alternative irrigating and draining) }\end{array}$ & 30 July $\sim 17$ September \\
\hline Heading stage & $\begin{array}{l}30 \text { July-10 August } \\
\text { (much water in the field, also called enlongation stage) } \\
11 \text { August }-24 \text { August } \\
\text { (less and less water in the field) } \\
25 \text { August }-17 \text { September } \\
\text { (flooding every other } 2 \text { or } 3 \text { days) }\end{array}$ \\
\hline 2nd Draining period & From 18 September \\
\hline Ripening stage & $\begin{array}{l}18 \text { September- } 8 \text { October } \\
\text { (no water in the field) }\end{array}$ \\
\hline Harvest & 9 October \\
\hline
\end{tabular}


planted to the flooded rice field on 25 May. Water level was kept at approximately $5 \mathrm{~cm}$ above the soil surface after transplanting. The dates of various field practices as well as the rice growing stages are listed in Tables 1 and 2.

The closed-chamber method was used for the measurement of phosphine emission fluxes from soil. Chambers were made of opaque plastics to avoid phosphine photo-degradation. During flux measurements, the boxes were put on their bottom stakes driven into the soil with a cross-sectional area of $0.25 \mathrm{~m}^{2}(50 \times 50 \mathrm{~cm})$. Each box contained eight bunches of rice plants. Two parallel plots were employed for flux measurements. A third plot with no rice planted in it served as the control. Chambers with an internal height of 50 $\mathrm{cm}$ were employed at the early stage, and taller chambers $(120 \mathrm{~cm}$ internal height $)$ were used afterward.

Before the chambers were placed on the stakes, it was necessary to mix the air in the chambers with ambient air by a small fan. A gas sample was taken with 50-ml disposable polypropylene-syringe immediately after the chamber was put on its stake. A second gas sample was taken usually $1 \mathrm{~h}$ after the first. Emission fluxes were determined from the temporal increase of phosphine concentration inside the chambers according to the following equation:

$$
\begin{aligned}
F & =\Delta Q /(S \Delta t)=V \Delta c /(S \Delta t) \\
& =S H \Delta c /(S \Delta t)=H \Delta c / \Delta t
\end{aligned}
$$

where $F$ is the flux or the emission rate in nanograms per square meter per hour; $c$ is the $\mathrm{PH}_{3}$ mass concentration in nanograms per cubic meter; $t$ is the sampling duration in hours; $H, S$ and $V$ are, respectively, the effective height, effective cross-sectional area and effective volume of a chamber in meters, square meters and cubic meters; and $\Delta Q$ is the difference of $\mathrm{PH}_{3}$ quantity existing in the chamber with time in nanograms.

A positive flux refers to phosphine emission from paddy field to the atmosphere, and a negative flux means phosphine absorption on soil particles, rice plants or paddy water (Ken-ich et al., 1992).

\subsection{Sample preparation and phosphine determination}

Details on sample preparation and phosphine determination have been published elsewhere (see Glindemann and Bergmann, 1995; 1996a). Gas samples in syringes were passed through a drying tube containing the MERCK 101567 drying agent (Merck KGaA, 64271 Darmstadt, Germany) for the removal of $\mathrm{H}_{2} \mathrm{O}, \mathrm{CO}_{2}$ and $\mathrm{H}_{2} \mathrm{~S}$. The phosphine in the samples was then enriched in two successive capillary cryo-traps at $-110^{\circ} \mathrm{C}$. The purified and enriched phosphine was then led into the GC injection port from the capillary traps through a 6-port valve.

A gas chromatograph HP-5890 was equipped with a capillary column (cross-linked $5 \% \mathrm{Ph} \mathrm{Me}$ Silicone, $25 \mathrm{~m} \times 0.2 \mathrm{~mm} \times 0.33 \mu \mathrm{m}$ film thickness, Hewlett-Packard). A thermo-ionic nitrogen-phosphorus-detector (NPD) was used for all phosphine determinations. Approximately $10 \sim 100 \mathrm{ml}$ of gas samples were cryo-trapped to reach a detection limit for phosphine of $0.1 \mathrm{ng} \mathrm{m}^{-3}$. Every sample was measured at least twice with a maximum deviation of approximately $20 \%$. A certified technical phosphine gas standard of $675 \mathrm{ppm}$

Table 2

Vertical profile of organic and total phosphorus in paddy soil (sampling on 8 December 1999)

\begin{tabular}{rllr}
\hline $\begin{array}{l}\text { Depth } \\
(\mathrm{cm})\end{array}$ & $\begin{array}{l}\text { Total phosphorus } \mathrm{P} \\
\left(\mathrm{g} \mathrm{kg}^{-1}\right)\end{array}$ & $\begin{array}{l}\text { Organic phosphorus } \mathrm{P}_{0} \\
\left(\mathrm{~g} \mathrm{~kg}^{-1}\right)\end{array}$ & $\begin{array}{l}\mathrm{P}_{0} / \mathrm{P} \\
(\%)\end{array}$ \\
\hline $0 \sim 10$ & 1.19 & 0.147 & 12.35 \\
$10 \sim 20$ & 0.97 & 0.050 & 5.17 \\
$20 \sim 30$ & 0.68 & 0.063 & 9.21 \\
$30 \sim 40$ & 0.55 & 0.044 & 7.98 \\
$40 \sim 50$ & 0.45 & 0.078 & 17.38 \\
\hline
\end{tabular}


(v/v) phosphine in nitrogen served for quantification. Both standard gas samples and the actual samples passed through the drying tube and cryo-traps, then entered the capillary column to reach the detector.

\subsection{Matrix-bound phosphine in the vertical profile of soil}

Matrix-bound phosphine is defined as the amount of phosphine liberated from sediment or soil samples during an acidic digestion. This treatment releases adsorbed phosphine, metal-phosphine-complexes, and inorganic phosphides. We used a preparative procedure very similar to that applied by food chemists for determining phosphine residues in fumigated cereals by digesting the samples in sulfuric acid (Nowicki, 1978). Soil cores $100 \mathrm{~cm}$ long were taken from the paddy field, and cut into $10-\mathrm{cm}$ segments. One gram of each segment was digested with $5 \mathrm{ml} 1 \mathrm{~N} \mathrm{H}_{2} \mathrm{SO}_{4}$
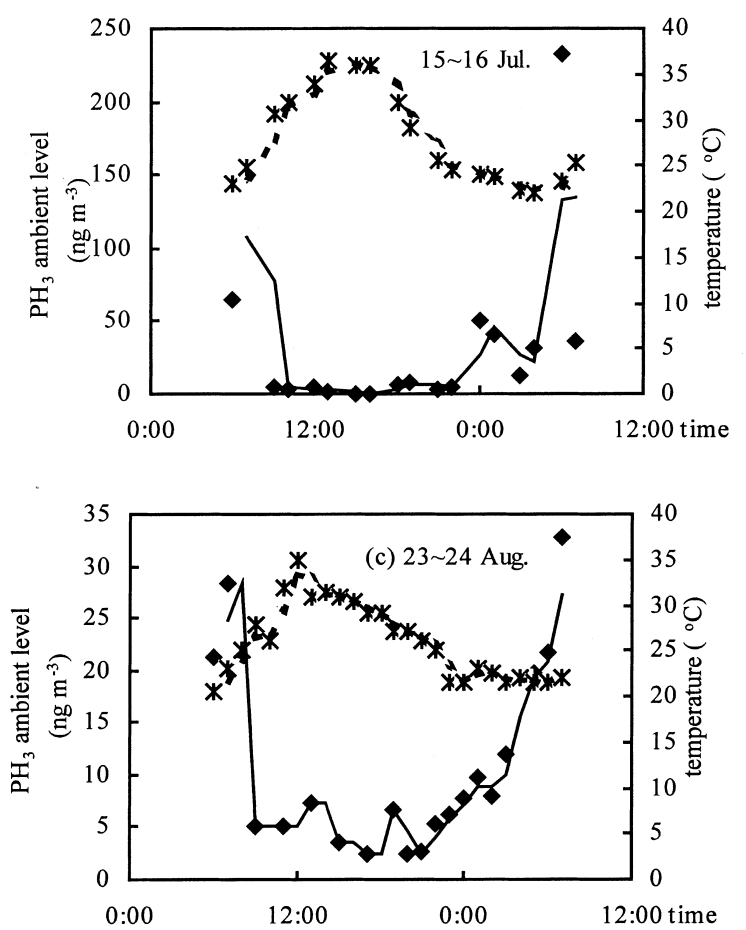

for $5 \mathrm{~min}$ at $100^{\circ} \mathrm{C}$ under an anoxic nitrogen atmosphere. The liberated phosphine was purged with $50 \mathrm{ml}$ pure nitrogen out of the reaction vessel into a 50-ml disposable polypropylenesyringe, from which it was directly transferred into the gas-chromatographic injection port after drying and cryo-trapping. The method for phosphine determination is the same as in Section 2.2.

We also determined total phosphorus and organic phosphorus in soil samples, following the procedures described in the Handbook of AgroChemistry Analysis (1984).

\section{Results and discussion}

\subsection{Diurnal and seasonal variations of phosphine ambient levels}

Fig. 1 shows the diurnal variation of phosphine ambient levels over the paddy field at different
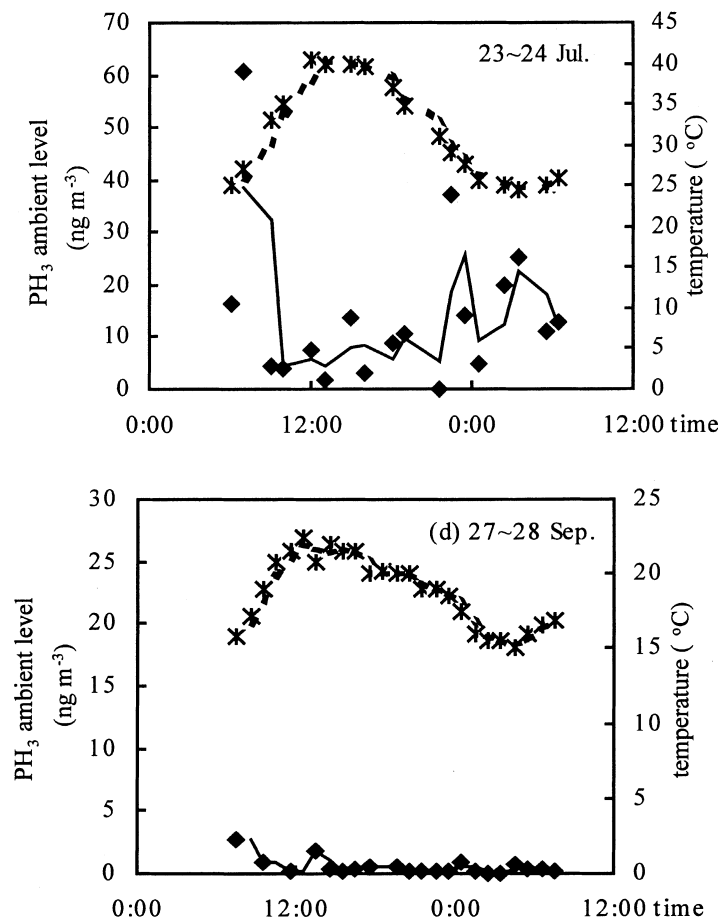

Fig. 1. Diurnal variation of $\mathrm{PH}_{3}$ ambient levels over paddy field; * temperature; $\bullet$ air; ---- 'temperature' trend line; — 'air' trend line; (a) in the middle of drainage (no water in the field); (b) at the end of drainage (no water in the field) (c) in the heading stage (water in the field); (d) before the harvest (no water in the field). 
stages of rice growth. The highest $\mathrm{PH}_{3}$ concentrations were observed in the early morning, whereas during daytime $\mathrm{PH}_{3}$ ambient levels were very low or even not detectable. The levels during night time were lower than at dawn. This clearly indicates an accumulation of phosphine in ambient air during the night time. After $08.00 \mathrm{~h}$, solar radiation became strong, and $\mathrm{PH}_{3}$ levels dropped abruptly due to its photo-degradation. In cloudy or rainy days, however, phosphine can still be detected at noon.

For comparison, it is worth mentioning that both $\mathrm{CH}_{4}$ and $\mathrm{H}_{2} \mathrm{~S}$ have their highest ambient levels in the time period between mid-night and early the next morning (Cooper et al., 1987; Cui et al., 1996).

The seasonal variation and ambient phosphine levels were measured at 06.00 and $07.00 \mathrm{~h}$. throughout the growing season of paddy rice. From Fig. 2, it can be seen that the seasonal variation was also significant, and was closely correlated with the alternative 'flooding' and 'draining' practices. During the drainage period from 2 July to 29 July, the paddy field was not covered by water. Thus, $\mathrm{PH}_{3}$ can be easily emitted from the surface soil layer because of the reduced diffusion resistance. It was in the drainage period that a soaring increase in ambient levels of $\mathrm{PH}_{3}$ from 16 to $250 \mathrm{ng} \mathrm{m}{ }^{-3}$ was observed. Since 30 July, the paddy field has become waterlogged again and the phosphine ambient levels in the morning dropped again. The seasonal variation pattern of phosphine ambient levels is also similar to those of hydrogen sulfide (Cooper et al., 1987).

\subsection{Diurnal and seasonal variations of $\mathrm{PH}_{3}$ emission fluxes}

Fig. 3 shows the diurnal variation of $\mathrm{PH}_{3}$ emission fluxes in the flooded period on 24-25 August and 27-28 September. Temperature, water, rice planting stage, etc. affect the $\mathrm{PH}_{3}$ emission flux.

August 24th and 25th belonged to the heading stage, when the paddy field was water logged, and the daily average temperature was high. On the contrary, September 27th and 28th were in the

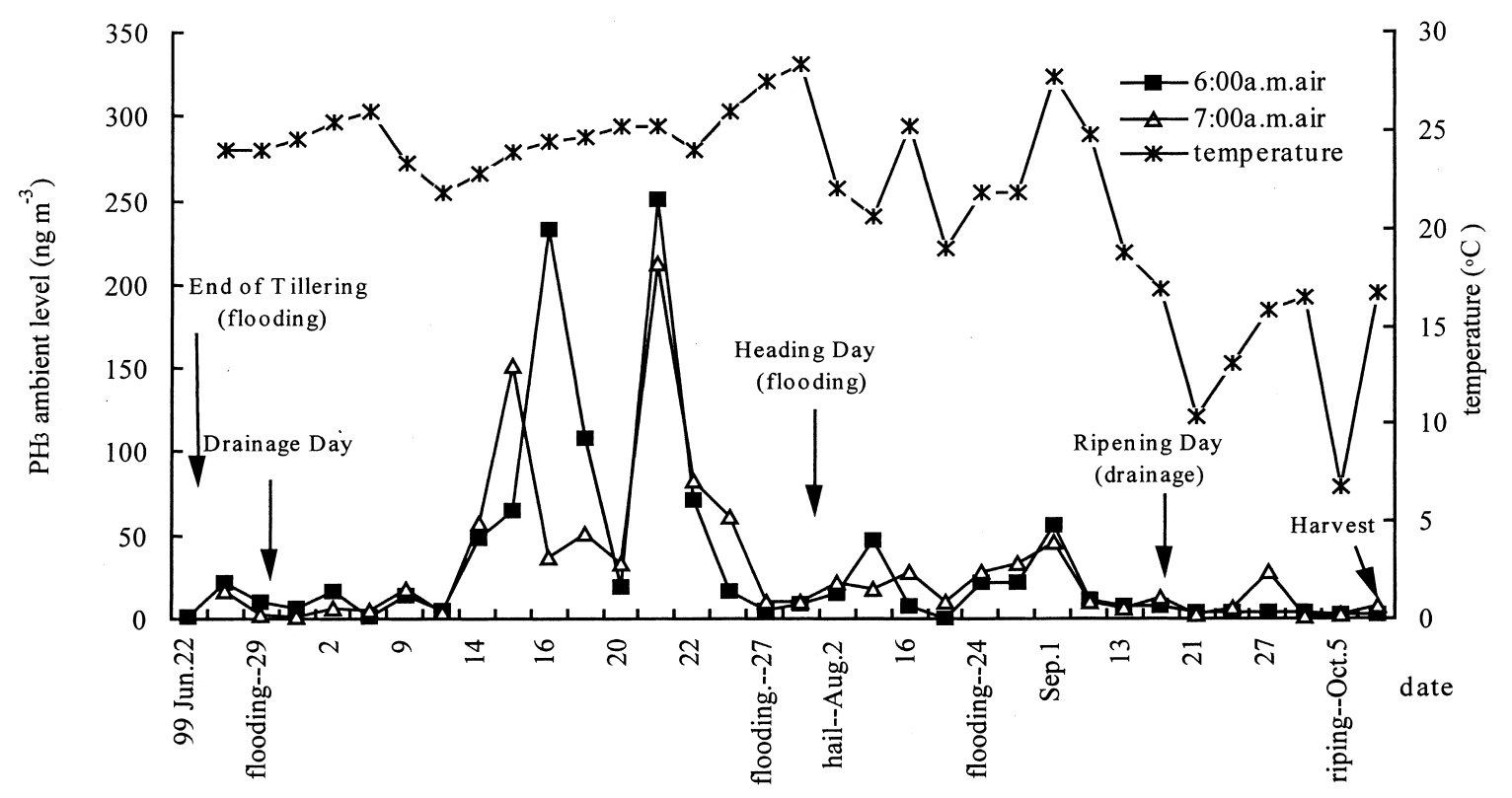

Fig. 2. Seasonal variation of $\mathrm{PH}_{3}$ ambient levels at $06.00 \sim 07.00 \mathrm{~h}$ over paddy field. Tillering stage from 25 May to $1 \mathrm{July}$; drainage period from 2 July to 29 July; heading stage from 30 July to 17 September; ripening stage from 18 September to 8 October. 

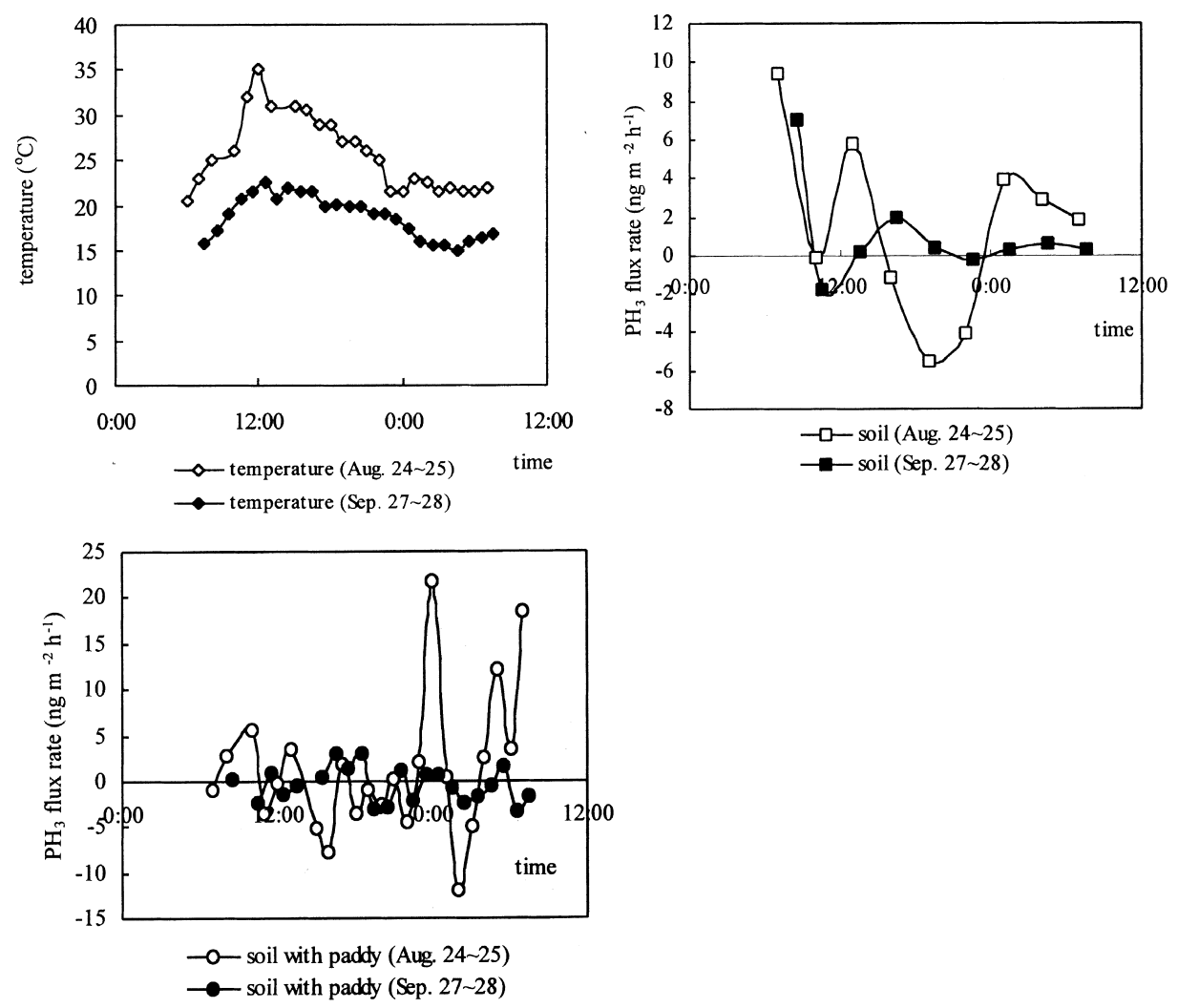

Fig. 3. Diurnal variation of $\mathrm{PH}_{3}$ emission fluxes.

ripening stage of rice. At that time, the field was scarcely covered with water, the temperature was lower than in August and the diurnal flux variation in the heading stage was more significant than that in the ripening stage.

Fig. 4 illustrates the seasonal variation of $\mathrm{PH}_{3}$ emission fluxes. There were three $\mathrm{PH}_{3}$ emission peaks in the whole growing season, namely, at the end of the tillering stage, in the middle of the drainage period, and at the end of the heading stage. The overall average flux during the whole growing season was $1.78 \mathrm{ng} \mathrm{m}^{-2} \mathrm{~h}^{-1}$. When the paddy field was drained between 2 July and 29 July, phosphine emission fluxes were higher than those in the flooded periods.

It seems that water played an important role in $\mathrm{PH}_{3}$ emissions. When the field was flooded, the soil was under anaerobic conditions. Net phosphine emission from planted paddy fields was mainly determined by the following four types of processes:

1. phosphine formation process controlled by anaerobic fermentation of organic phosphorus-containing precursors and by soil temperature;

2. phosphine storage process turning phosphine into a matrix-bound form;

3. phosphine oxidation process including microbial oxidation, chemical oxidation and photo-oxidation; and

4. gas transport processes including diffusion through soil pores and through the vascular bundle in rice stems.

Whenever phosphine formation and/or transport are inefficient, most of the phosphine produced is oxidized and/or stored in soil and hence, 


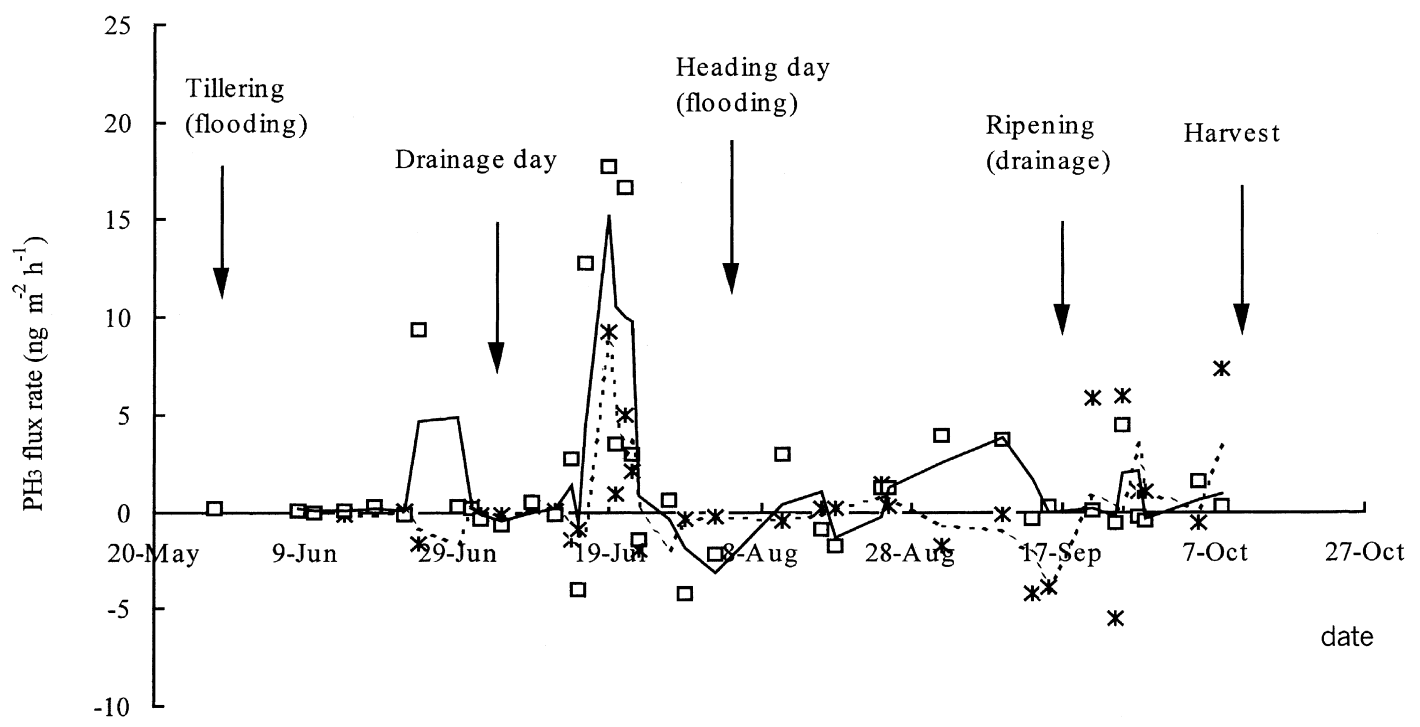

Fig. 4. Seasonal variation of $\mathrm{PH}_{3}$ emission fluxes; * bare soil; $\square$ soil with paddy; ----- bare soil trend line; —— soil with paddy trend line. Tillering stage from 25 May to 1 July; drainage period from 2 July to 29 July; heading stage from 30 July to 17 September; ripening stage from 18 September to 8 October.

the flux is low. On the other hand, when phosphine formation rate is high, or gas transport is efficient, a substantial amount of phosphine will be able to reach the atmosphere, and the emission flux is high.

The complex combination of the above processes is responsible for both the seasonal and diurnal variation patterns reported here. During the flooding period, phosphine can be formed readily owing to the anaerobic condition, but its transport was restricted. Phosphine can either diffuse through the vascular bundle in the rice stems or intermittently come out in methane bubbles. So its flux during the flooded period was not large, and was fluctuating. On the other hand, during the drainage period the accumulated phosphine can be released freely from the dried soil. This led to a large peak at the beginning of the drainage period. In the later days of the drainage period, no more phosphine was emitted because of the aerobic conditions in the surface soil layer. The matrix-bound phosphine became exhausted too. Hence, the flux went down abruptly.

We postulate that the stomata may close during mid-day. The gas transport pathway is blocked in the afternoon during the flooded period; mean- while the closure of plant stomata may also prevent the transport of oxygen to the root system and enhance the storage of phosphine in the afternoon. After sunset, the reopening of stomata may enable transport of accumulated phosphine to the atmosphere.

\subsection{The vertical profiles of matrix-bound phosphine and total phosphorus in soil}

Soil samples were collected at the end of the drainage period - 20 July - and also before harvest - 21 September 1999. The highest content of matrix-bound $\mathrm{PH}_{3}$ was found in the layer at $-10 \sim-20 \mathrm{~cm}$, it was approximately $7 \mathrm{ng}$ $\mathrm{kg}^{-1}$ (dry wt., see Fig. 5). Since $\mathrm{PH}_{3}$ in the surface layer can either diffuse into the air or can be oxidized readily, the surface layer $(0 \sim-10 \mathrm{~cm})$ contained less matrix-bound $\mathrm{PH}_{3}$ than the layer at the depth of $-10 \sim-20 \mathrm{~cm}$. With increasing depth, the amount of matrix-bound $\mathrm{PH}_{3}$ declined. In the deeper layers, matrix-bound $\mathrm{PH}_{3}$ approached zero. On the day before harvest (Fig. 6), the lower ambient temperature might lead to slower $\mathrm{PH}_{3}$ emission from the surface soil layer.

At our experimental site, the farmers used do- 


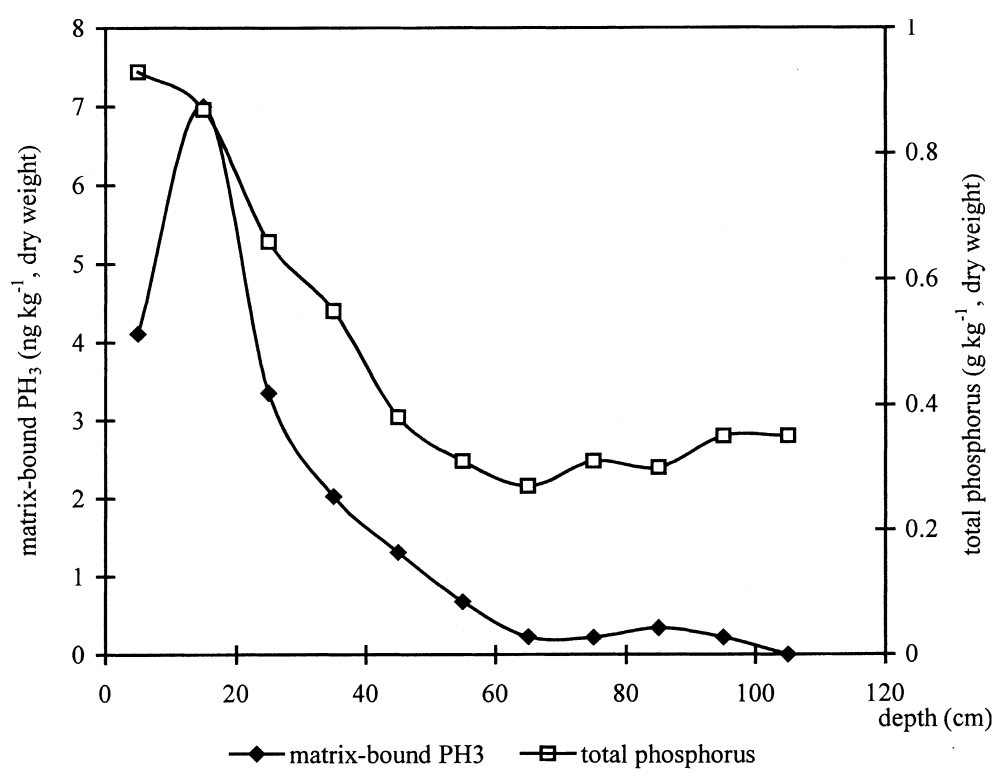

Fig. 5. The vertical profile of matrix-bound $\mathrm{PH}_{3}$ and total phosphorus in soil (on 20 July 1999 from 0 to $-110 \mathrm{~cm}$ ).

mestic sewage for irrigation and fertilization. The sewage water had a rather high phosphorus content hence, higher organic phosphorus content and total phosphorus content were observed in the cultivated layer from 0 to $30 \mathrm{~cm}$ depth.
The matrix-bound phosphorus produced under the anaerobic condition and adsorbed by soil consists of approximately $0.18 \sim 1.42 \times 10^{-7}$ mass fraction of organic phosphorus or $3.4 \sim 9.2 \times 10^{-9}$ mass fraction of total phosphorus in paddy soil.

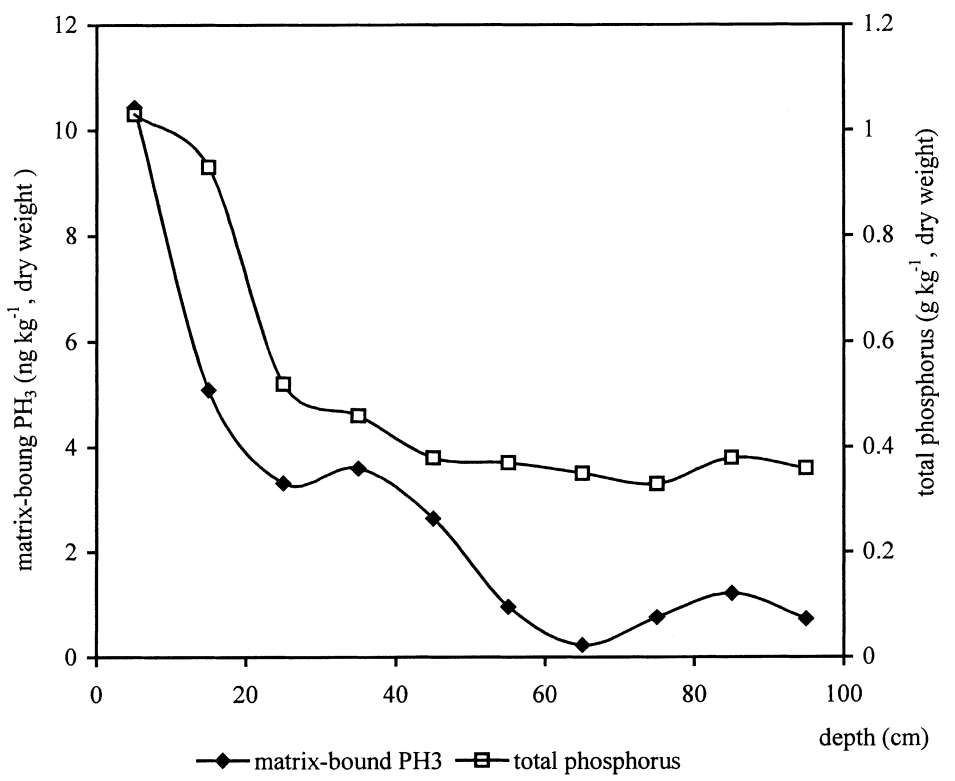

Fig. 6. The vertical profile of matrix-bound $\mathrm{PH}_{3}$ and total phosphorus in soil (on 21 September 1999 from 0 to $-100 \mathrm{~cm}$ ). 
This part of matrix-bound $\mathrm{PH}_{3}$ is vulnerable to oxidation and may have a significant impact on water-bodies. Storm run-off from croplands or stirring-up of sediments in water bodies would bring the matrix-bound phosphine into the surface layers of the water bodies, where the matrixbound phosphine is easily converted into phosphoric acid or phosphate ions in the presence of oxygen and solar radiation. These inorganic phosphates can readily be uptaken by algae or phytoplankton. Hence, matrix-bound phosphorus might play an important role in lake eutrophication and red tide formation induced by the so-called 'chemical time bomb effect' (Stigniali et al., 1991).

\section{Conclusions}

1. The diurnal and seasonal variations of $\mathrm{PH}_{3}$ ambient levels over paddy fields are reported for the first time. Higher ambient $\mathrm{PH}_{3}$ levels were observed at mid-night and in the early morning. The highest $\mathrm{PH}_{3}$ level occurred on the first drainage day, namely the day after the tillering period.

2. The diurnal and seasonal variations of $\mathrm{PH}_{3}$ emission fluxes from paddy field are reported. The diurnal variation depends on waterlogging and soil temperature, whereas the seasonal variation is closely related to the flooding and drainage practices during rice cultivation. $\mathrm{PH}_{3}$ fluxes follow a fluctuation pattern.

3. Matrix-bound $\mathrm{PH}_{3}$ can be detected in the cultivated soil layer. The amount of matrixbound $\mathrm{PH}_{3}$ in paddy soil consists of approximately $0.18 \sim 1.42 \times 10^{-7}$ mass fraction of the organic phosphorus, or $3.4 \sim 9.2 \times 10^{-9}$ (mass fraction) of total phosphorus in paddy soil.

\section{Acknowledgements}

This work was supported by the National Natural Science Foundation of China (Grant No. 39790100). We appreciate the farmers of Houba- jia for allowing us to use their paddy field for our experiments.

\section{References}

Cao HF, Liu JA, Zhuang YH. Emission sources of atmospheric phosphine and the stimulation of phosphine formation. Sci Chin (Series B) 2000;43(2):162-168.

Cooper WJ, Cooper DJ, Saltman ES, de Mello WZ, Savoie DL. Emission of biogenic sulphur compounds from several wetland soils in Florida. Atmos Environ 1987;21(7): 1491-1495.

Cui P, Yao H, Qi LW. $\mathrm{CH}_{4}$ concentration detection in the air of paddy field of Beijing. Huan Jing Ke Xue 1996;17(2): 26-28.

David I, Felfody L, Wittner I. Detection of phosphine: new aspects of the phosphorus cycle in the hydrosphere. Nature 1988;333:343-345.

Devai I, Delaune RD. Evidence for phosphine production and emission from Louisiana and Florida marsh soils. Org Geochem 1995;23:277-279.

Eismann F, Glindemann D, Bergmann A, Kuschk P. Balancing phosphine in manure fermentation. J Environ Sci Health 1997b;B32(6):955-968.

Gassmann G, Schorn F. Phosphine from harbor surface sediment. Naturwissenschaften 1993;80:78-80.

Gasmann G. Phosphine in fluvial and marine hydrosphere. Mar Chem 1994;45:197-205.

Glindemann D, Bergmann A. Spontaneous emission of phosphine from animals slurry treatment processing. Zbl Hyg 1995;198:49-56.

Glindemann D, Bergmann A, Stottmeister U, Gassmann G. Phosphine in the lower terrestrial troposphere. Naturwissenschaften 1996a;83:131-133.

Glindemann D, Stottmeister U, Bergmann A. Free phosphine from the anaerobic biosphere. Sci Pollut Res 1996b;3(1): 17-19.

Li YK, editor. Handbook of agro-chemistry analysis. Beijing, 1984

Ken-ich K, Haruo T, Katsuyuki M. Emission of dimethyl sulfide, carbonyl sulfide, and carbon disulfide from paddy fields. Soil Sci Plant Nutr 1992;38(4):709-716.

Liu JA, Cao HF, Zhuang YH et al. Phosphine in the urban air of Beijing and its possible source. Water Air Soil Pollut 1999;166(3/4):597-604.

Nowicki TW. Gas-liquid-chromatographic and flame photometric detection of phosphine in wheat. J Ass Anal Chem 1978;61:829-836.

Prinn RG. The interactive atmosphere: global atmosphericbiosphere chemistry. Ambio 1994;23:50-61.

Stigniali WL, Dodman P, Salomons W, Schulin R, Smidt GRB, Van der Zee, SEATM. Chemical time bombs. Environment 1991; 33(4): 4-9, 26-30.

Tsubota G. Phosphate reduction in the paddy field I. Soil Plant Food (Tokyo) 1959;5:10-15. 